\title{
N-TERMINAL SEQUENCE OF CREATINE KINASE FROM SKELETAL MUSCLE OF RABBIT AND RHESUS MONKEY
}

\author{
W. Richard Chegwidden ${ }^{\prime *}$, David Hewett-Emmett ${ }^{2}$ and Gerald G. Penny ${ }^{\prime}$ \\ 'Departments of Biological Sciences and Chemistry, Sheffield City Polytechnic. Pond Street, \\ Sheffield S1 IWB, U.K. \\ ${ }^{2}$ Department of Human Genetics, University of Michigan Medical School, Ann Arbor, MI 48109, U.S.A.
}

(Received 14 August 1984)

\begin{abstract}
The first 20 amino acids from the $\mathrm{N}$-terminus of skeletal muscle (MM) creatine kinase from both rabbit and rhesus monkey have been identified and these sequences show considerable homology. 2. Contrary to an earlier report, the N-terminus was not found to be blocked.

3. Both of these sequences show much less homology with the $\mathrm{N}$-terminal sequence of heart muscle (MM) creatine kinase and no homology with that of the heart muscle mitochondrial (MiMi) isozyme. 4. No homology was found between the N-terminal sequence of the mitochondrial isozyme and the URF (unidentified reading frame) proteins of the human mitochondrial genome, indicating that the mitochondrial enzyme is encoded by nuclear genes. This suggests the possibility that an $\mathrm{N}$-terminal peptide may be cleaved from the mitochondrial isozyme on its translocation across the mitochondrial membrane.
\end{abstract}

\section{INTRODUCTION}

Creatine kinase (adenosine-5'-triphosphate creatine phosphotransferase, EC 2.7.3.2) catalyses the reaction:

$$
\begin{aligned}
\text { creatine }^{ \pm}+\mathrm{MgATP}^{2-} & \underset{+\mathrm{MgADP}^{-}}{\rightleftharpoons} \mathrm{Mgsphocreatine}^{2-}+\mathrm{H}^{+} .
\end{aligned}
$$

Present in a wide variety of vertebrate tissues, it is particularly abundant in muscle and nerve and is generally associated with ATP regeneration in contractile and transport processes (Watts, 1973).

The enzyme was first crystallized from rabbit skeletal muscle (Kuby et al., 1954) and shown to comprise two identical sub-units (MM) of total mol. wt 82,600 (Olson and Kuby, 1964; Yue et al., 1967). In addition to this muscle type isozyme (MM), two other electrophoretically distinguishable forms, the brain type (BB) and hybrid (MB), were originally discovered and characterized (Eppenberger et al., 1964). Subsequently, a fourth type of creatine kinase was found in mitochondria (Jacobs et al., 1964: Jacobus and Lehninger, 1973) and this appears to comprise two identical sub-units (MiMi) distinct from the muscle and brain subunit types (Blum et al., 1983).

Surprisingly little information has been reported regarding the primary structure of the enzyme (Watts, 1973; Kenyon and Reed, 1983) and this has largely been directed at a short sequence containing the reactive thiol group. This particular sequence of some 13 amino acids has been determined in creatine kinase from rabbit muscle (Thomson et al., 1964), human and ox muscle (Thomson et al., 1968), normal and dystrophic human muscle (Palmieri et al., 1971), normal and dystrophic chicken breast muscle (Roy, 1974) and rabbit and ox brain (Atherton et al., 1970a,

*To whom correspondence should be addressed at the Department of Biological Sciences, Sheffield City Polytechnic. 1970b) and is almost identical in all cases. The comparable sequences in lobster arginine kinase (Der Terrosian et al., 1969) and in earthworm lombricine kinase (Der Terrosian et al., 1971) are also very similar.

The C-terminal dipeptide of the rabbit muscle enzyme has been identified using carboxypeptidase and its removal does not affect catalytic activity (Olson and Kuby, 1964).

Recently Blum et al. (1983) have sequenced the first 11 amino acids of the human heart mitochondrial isozyme (MiMi) and the first 15 amino acids of the human heart muscle (MM) isozyme. Otherwise the primary structure has not received further attention. In contrast to Blum et al. (1983), Mahowald and Kuby (1960) reported that they were unable to identify the $\mathrm{N}$-terminal amino acid by either the fluorodinitrobenzene or phenylisothiocyanate procedures employing both native and guanidinedenatured enzyme, implying that the $\mathrm{N}$-terminus was modified. In the present study we did not find this to be the case and we now report the sequence of the first 20 amino acids of creatine kinase from both rabbit (Oxycytolagus cunniculus) and rhesus macaque monkey (Macaca mulatta) skeletal muscle, which we compare with the sequences of Blum et al. (1983).

\section{MATERIALS AND METHODS}

Creatine kinase from rabbit skeletal muscle was prepared by method B of Kuby et al. (1954) using Anala R ethanol treated as described by Nihei et al. (1961).

Creatine kinase from rhesus monkey skeletal muscle was prepared by the method of Chegwidden and Watts (1975) followed by further purification on a Sephadex G-75 column in $0.002 \mathrm{M}$ Tris-Cl buffer, $\mathrm{pH} 8.3$.

Sequence analysis was performed using a Beckman Model $890 \mathrm{~B}$ automatic sequencer as described by Henriksson et al. $(1980)$. The PTH derivatives were identified by HPLC (Kageoka et al, 1981) with the exception of PTH histidine which was identified by Pauly's diazo method (Niall, 1974). 


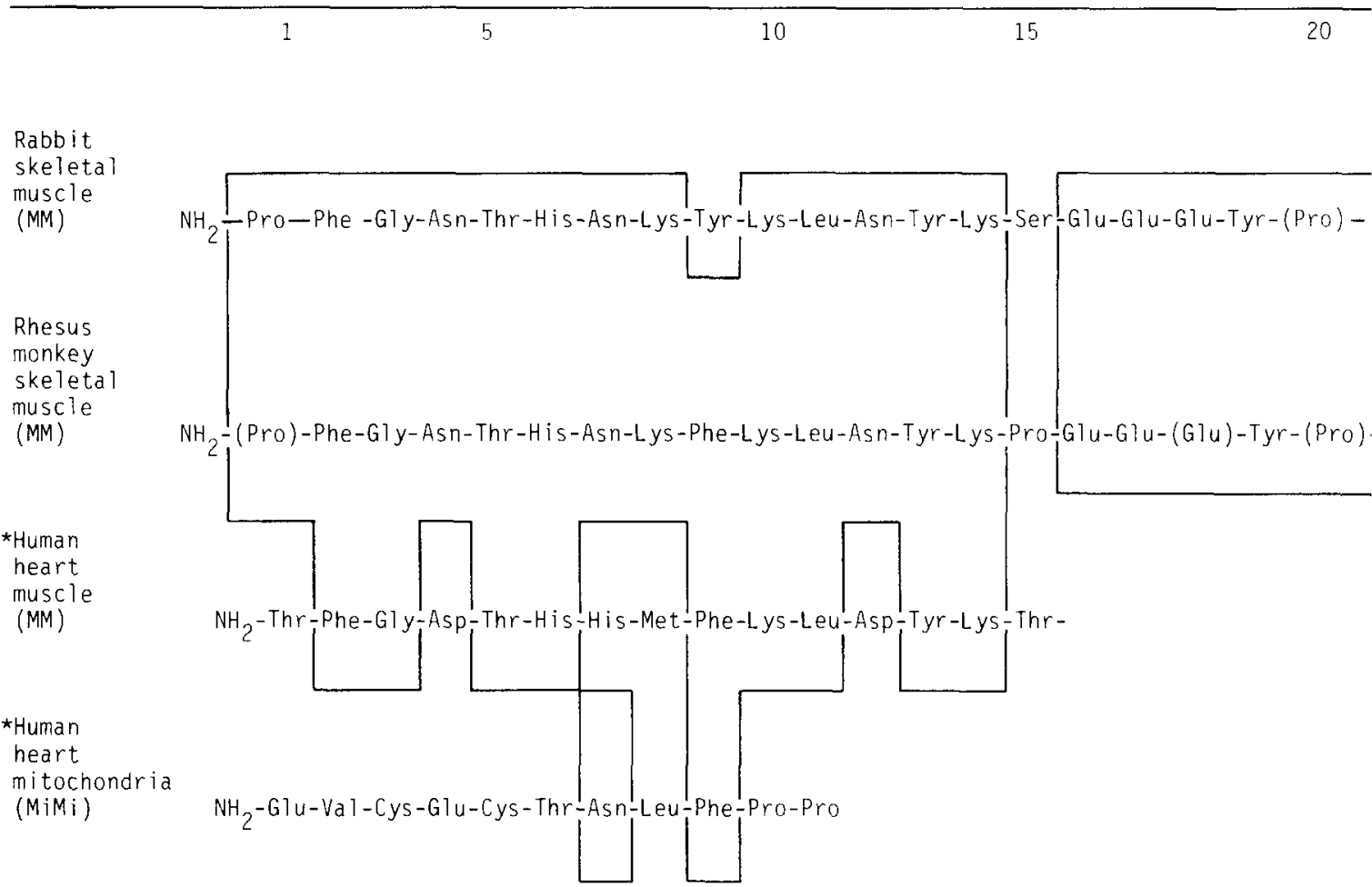

Fig. 1. N-terminal amino acid sequences of rabbit, rhesus monkey and human creatine kinase isozymes. Residues in parentheses are tentative. Identical residues are boxed. *From Blum et al. (1983).

\section{RESULTS AND DISCUSSION}

The first 20 amino acids of skeletal muscle (MM) creatine kinase from both rabbit and rhesus monkey have been identified. In Fig. 1 these sequences are compared with the N-terminal sequences of the human heart muscle (MM) and human heart mitochondrial (MiMi) isozymes recently reported by Blum et al. (1983).

Considerable homology is evident between the rabbit and rhesus monkey sequences, with only two amino acid changes, each requiring only one nucleotide base mutation, among the 20 residues identified. Positions 9 and 15, occupied by tyrosine and serine respectively in the rabbit enzyme, are occupied by phenylalanine and proline in the rhesus monkey enzyme (Fig. 1).

Comparison of our rhesus monkey muscle sequence with the human heart muscle sequence, which may be expected to the more closely related to each other than either is to the rabbit, reveals a surprisingly different picture with six amino acid differences among the 15 residues sequenced in both. Four of these apparent differences are perhaps open to some question. In the present study, positions 4 and 10 of both the rabbit and rhesus monkey enzymes were found to be occupied by asparagine (Fig. 1 ). The aspartic acid found in both these positions in the human muscle enzyme by Blum et al. (1983) may be an artefact due to deamidation (cf. Niall, 1974). Also, no mention is made by Blum et al. (1983) of their method of identification of the PTH derivatives.
If they employed gas chromatography then discrimination between threonine and proline can be very difficult by this method, which may well explain the apparent differences at positions 1 and 15 (Fig. 1).

The N-terminal sequence of mitochondrial creatine kinase (MiMi) from human heart muscle is completely different from the sequence in the muscle type (MM) isozymes, with the exception of position 9 which is occupied by phenylalanine in all but the rabbit muscle isozyme and position 7 which is occupied by asparagine in all but the human heart muscle isozyme. Furthermore, four of the amino acid differences in the mitochondrial enzyme, among the 11 residues sequenced, would require at least two base changes. Williamson et al. (1977) have identified two different components of rabbit muscle creatine kinase of slightly different size, differing in length by about 15 amino acids. It is worth noting, however. that the mitochondrial sequence does not match any part of the first 15 amino acids of the human heart muscle or the first 20 of the rhesus monkey muscle isozyme.

There are several plausible explanations for these differences in sequence. Perhaps through a long period of evolutionary divergence, one isozyme has emerged with a relatively truncated terminus. Alternatively, differential proteolysis of the mitochondrial and muscle isozymes may occur, either as an artefact of isolation or as a normal post-translational modification.

No region of homology was found between the N-terminal sequence of the mitochondrial creatine 
kinase and the URF (unidentified reading frame) proteins of the human mitochondrial genome sequenced by Anderson et al, (1981), which indicates that the mitochondrial isozyme is encoded by nuclear genes and post-translationally transported into the mitochondria. In such cases, cleavage of a "signal" peptide commonly occurs on translocation across the mitochondrial membrane (Henning and Neuport, 1983; Suominen and Mäntsälä, 1983), although this has been shown not to be so in the case of cytochrome c (Hennig et al., 1983) which enters the mitochondria intact.

The $\mathrm{N}$-terminal residue of rabbit muscle creatine kinase was unambiguously identified as proline (Fig. 1) and although position 1 in the rhesus monkey enzyme, uniquely amongst those identified, showed an elevated level of several PTH derivatives, the most pronounced elevation was also in PTH proline. These findings, however, are not necessarily inconsistent with those of Mahowald and Kuby (1960) who were unable to identify an N-terminal amino acid. Quite possibly the enzyme may be synthesized with a blocked $\mathrm{N}$-terminus, the free $\mathrm{N}$-terminal amino acid observed in the present study being produced by subsequent exposure to a hydrolase after the cells were disrupted in the isolation procedure. It is certainly a tenable hypothesis that muscle proteins with blocked N-termini are the normal in vivo products of biosynthesis and several stages of post-translational modification may well occur (Wold, 1984). The identification by Williamson et al. (1977) of the two different components of rabbit muscle creatine kinase may possibly be related to this type of process. Trangott and Massaro (1973), using starch gel electrophoresis, have also detected several sub-bands of M-type sub-units. which still persisted following reversible urea denaturation indicating more than conformational differences. Undoubtedly the extended use of nucleotide sequencing techniques, in conjunction with $\mathrm{N}$-terminal amino acid sequencing such as that presented here, will play a major part in resolving this general question (Wold, 1984).

\section{Note added in proof}

Subsequent to the acceptance of this paper for publication the cDNA sequence of rabbit muscle creatine kinase, with translated polypeptide sequence, has been published (Putney et al.. 1984). These data confirm the results presented here.

Achnowledgements - We wish to thank Dr Richard E. Tashian for use of protein sequencing facilities and for his valuable advice. Financial assistance (to W.R.C.) from the Wellcome Trust and the Nuffield Foundation is gratefully acknowledged.

\section{REFERENCES}

Anderson S., Bankier A. T., Barrell B. G., de Bruijn M. H. L., Coulson A. R., Drouin J., Eperon I. C., Nierlich D. P., Roe B. A., Sanger F., Schreier P. H., Smith A. J. H., Staden R. and Young I. G. (1981) Sequence and organization of the human mitochondrial genome. Nature, Lond. 290, 457-465.

Atherton R. S., Laws J. F., Miles B. J. and Thomson A. R. (1970a) Brain adenosine 5'-triphosphate creatine phosphotransferase. Purification, thiol group reactivity and the amino acid sequence around the reactive thiol group. Biochem. J. 120, 589-600.

Atherton R. S., Laws J. F., Miles B. J. and Thomson A. R. (1970b) Bovine brain creatine phosphotransferase amino acid sequence and the essential thiol group Biochem. $J$. 117, 30P-31P

Blum H. E., Deus B. and Gerok W. (1983) Mitochondrial creatine kinase from human heart muscle: purification and characterization of the crystallized isoenzyme. $J$. Biochem. 94, 1247-1257.

Chegwidden W. R. and Watts D. C. (1975) Kinetic studies and effects of anions on creatine phosphokinase from skeletal muscle of rhesus monkey (Macaca mulatta). Biochim. biophys. Acta 410, 99-114.

Der Terrosian E., Desvages G., Pradel L. A., Kassab R. and Van Thoai N. (1971) Comparative structural studies of the active site of ATP: guanidine phosphotransferases. The essential cysteine tryptic peptide of lombricine kinase from Lumbricus terrestris muscle. Eur. J. Biochem. 22, $585-592$.

Der Terrosian E., Pradel L. A.. Kassab R. and Van Thoai N. (1969) Comparative structural studies of the active site of ATP: guanidine phosphotransferases. The essential tryptic peptide of argine kinase from Homarus iulgaris muscle. Eur. J. Biochem. 11, 482-490.

Eppenberger H. M., Eppenberger M., Richterich R. and Aebi H. (1964) The ontogeny of creatine kinase isozymes. Devl. Biol. 10, 1-16.

Hennig B., Koehler H. and Neupert W. (1983) Receptor sites involved in post-translational transport of apocytochrome $c$ into mitochondria: Specificity, affinity and number of sites. Proc. natn. Acad. Sci., U.S.A. 80, 4963-4967.

Hennig B. and Neupert W. (1983) Assembly of mitochondrial proteins. In Horizons in Biochemistry and Biophysics (edited by Quagliariello E., Palmieri F. and Singer T. P.), Vol. 7, pp. 307-346. John Wiley, New York.

Henrikkson D., Tanis R. J. and Tashian R. E. (1980) The amino acid sequence of carbonic anhydrase $I$ from the rhesus macaque. Biochem. biophys. Res. Commun. 96, $135-142$.

Jacobs H., Heldt H. W. and Klingenberg M. (1964) High activity of creatine kinase in mitochondria from muscle and brain and evidence for a separate mitochondrial isoenzyme of creatine kinase. Biochem. biophys. Res. Commun. 16, 516-521.

Jacobus W. E. and Lehninger A. L. (1973) Creatine kinase of rat heart mitochondria. Coupling of creatine phosphorylation to electron transport. J. biol. Chem. 248, 4803-4810

Kageoka T., Hewett-Emmett D., Stroup S. K., Yu Y-S. L and Tashian R. E. (1981) Amino acid substitution and chemical characterization of a Japanese variant of carbonic anhydrase I: CA I Hiroshima-1 (86 Asp $\rightarrow$ Gly). Biochem. Genet. 19, 535-549.

Kenyon G. L. and Reed G. H. (1983) Creatine kinase: structure-activity relationships. In Aduances in Enzymologv (Edited by Meister A.). In Vol. 54, pp. 367-426. John Wiley, New York.

Kuby S. A., Noda L. and Lardy H. A. (1954) Adenosinetriphosphate-creatine transphosphorylase. I. Isolation of the crystalline enzyme from rabbit muscle. J. biol. Chem. 209, 191-201.

Mahowald T. A. and Kuby S. A. (1960) Studies on ATPtransphosphorylases. Fedn Proc., Fedn Am. Socs exp. Biol. 19, 46

Niall H. D. (1974) Automated Edman degradation: the protein sequenator. Meth. Enzym. 27, 942-1010.

Nihei T., Noda L. and Morales M. F. (1961) Kinetic properties and equilibrium constant of the adenosine triphosphate-creatine transphosphorylase-catalyzed reaction. J. biol. Chem. 236, 3202-3209.

Olson O. E. and Kuby S. H. (1964) Studies on adenosine 
triphosphate transphosphorylases. V Carboxy terminal sequences of adenosine triphosphate-creatine transphosphorylase and of adenosine triphosphate-adenosine $5^{\prime}$ phosphate transphosphorylase (myokinase). J. biol. Chem. 239, 460-467.

Palmieri R., Keutel H., Jacobs H., Okabe K., Yue R., Ziter F., Tyler F. and Kuby S. A. (1971) A further comparison of normal human ATP creatine transphosphorylases with those from progressive muscular dystrophic tissues. Fed $n$ Proc., Fedn Am. Socs exp. Biol. 30, 1255.

Putney S. et al. (1984) Rabbit muscle creatine phosphokinase. cDNA cloning, primary structure and detection of human homologues. J. biol. Chem. 259, 14317-14320.

Roy B. P. (1974) The amino acid sequence of the peptide containing the thiol group of creatine kinase from normal and dystrophic chicken breast muscle. Biochem. J. 143, $171-179$.

Suominen I, and Mäntsälä P. (1983) Translocation of proteins across membranes. Int. J. Biochem. 15, 591-601.

Thomson A. R., Eveleigh J. W., Laws J. F. and Miles B. J. (1968) The comparative biochemistry of mammalian creatine phosphotransferases. In Homologous Enzymes and Biochemical Evolution (Edited by Van Thoai N. and Roche J.), pp. 255-275. Gordon \& Breach, New York.
Thomson A. R., Eveleigh J. W. and Miles B. J. (1964) Amino acid sequence around the reactive thiol groups of adenosine triphosphate-creatine phosphotransferase. Nature, Lond. 203, 267-269.

Trangott C. and Massaro E. J. (1973) The molecular basis of the heterogeneity of the MM isozyme of rabbit muscle creatine phosphokinase. Biochim. biophys. Acta 295. 549-554.

Watts D. C. (1973) Creatine kinase. In The Enzimes (Edited by Boyer P. D.). Vol. 8. pp. 383-455. Academic Press. New York.

Williamson J., Greene J., Chérif S. and Milner-White E. J. (1977) Heterogeneity of rabbit muscle creatine kinase and limited proteolysis by proteinase K. Biochem. J. 167, $731-737$.

Wold F. (1984) Acetylated N-terminals in proteins-a perennial enigma. Trends Biochem. Sci. 9(6), 256-257.

Yue R. H., Palmieri R. H., Olson O. E. and Kuby S. A (1967) Studies on adenosine triphosphate transphosphorylases. V Studies on the polypeptide chains of the crystalline adenosine triphosphate-creatine transphosphorylase from rabbit skeletal muscle. Biochemistry 6, 3204-3227. 